\title{
Study of Cleft Lip and Palate in Kathmandu Model Hospital, Nepal
}

\author{
Dr Sanzida Khatun \\ Lecturer, Department of Anatomy, Nobel Medical College, Biratnagar, Nepal \\ Correspondence: Dr Sanzida Khatun; Email: ksanzida12@gmail.com
}

\section{ABSTRACT}

Introduction: Cleft lip and/or palate is a congenitally persistent space affecting orofacial region. It is generally divided into cleft lip (CL), cleft palate (CP) and cleft lip with cleft palate (CLP). The objective of the study was to evaluate distribution of patterns of orofacial clefts according to sex and laterality; predisposing factors and other congenital anomalies associated with cleft lip and/or palate.

Materials \& Method: A cross-sectional descriptive type of study was carried out using in 268 patients having cleft lip and/or palate. Types of clefts, predominance of sex and laterality, familial history, associated anomalies and drug and disease history of mother were recorded.

Result: The results revealed $23.51 \%$ CL, $54.85 \%$ CLP and $21.64 \%$ CP. There were $58.21 \%$ males and $41.79 \%$ females. Positive family history of cleft was present in $28.0 \%$ and associated anomalies were observed in $3.7 \%$ of the cleft subjects. Mothers of $6.0 \%$ of the total patients were exposed to teratogenic agents during first trimester of pregnancy.

Conclusion: It was concluded that among the three types of cleft (CL, CP and CLP), CLP is the most common type. The males are affected more with cleft lip and/or palate than the females. Clefts also have risks of associated congenital anomalies. Exposure to teratogenic agents in first trimester of pregnancy is also associated with orofacial cleft.

Keywords: cleft lip, cleft lip and palate, cleft palate, congenital anomalies, craniofacial malformations, orofacial defects

\section{INTRODUCTION}

Cleft lip and/or palate is a congenitally persistent space in the upper lip, alveolus, hard palate or soft palate associated with dental malocclusion, nasal deformity, feeding problems, hearing deficit and speech difficulties. Many teratogenic factors in pregnancy are now claimed to contribute in causing clefts, such as maternal smoking, ${ }^{2}$ hypoxia, maternal age, season of gestation, ${ }^{3}$ maternal diabetes mellitus ${ }^{4}$ and viral infection. ${ }^{5}$

A child with cleft is born every 2 minutes in the world. Its incidence varies with geography, race, sex and socioeconomic condition. ${ }^{6}$ In a retrospective study conducted in Eastern Nepal, the incidence of cleft lip and/or palate was 1.64/1000 live births per year. ${ }^{7}$ It requires a more distinct understanding regarding cleft condition so that optimal treatment can be planned. ${ }^{8}$

This study was aimed to study distribution of patterns of orofacial clefts according to sex and laterality; predisposing factors and other congenital anomalies associated with cleft lip and/or palate.

\section{MATERIALS AND METHOD}

A descriptive type of cross-sectional study was conducted in Kathmandu Model Hospital, Exhibition Road,
Kathmandu, Nepal. The ethical approval was received from Nepal Medical College, Kathmandu, Nepal. The subjects included patients under 18 years of age group who presented to out-patient department of plastic surgery of Kathmandu Model Hospital in 2014 A.D. seeking medical/ surgical intervention.

Sample size was calculated using the formula for estimating population proportion for cross-sectional study:

$$
n 1=\frac{\left(z^{2} \times p q\right)}{d^{2}} \quad \text { Equation } 1
$$

where, $\mathrm{nl}$ is the required number of sample size $z$ is the factor to achieve $95 \%$ level of confidence $(z=1.96)$; $\mathrm{p}$ is the prevalence

$\left(p=1.64\right.$, taken from previous studies $\left.{ }^{7}\right)$;

$d$ is the absolute margin of error $[d=(20 \%$ of $p)=0.107]$;

The sample size derived was 5791.5. However, the sample size was adjusted by using Modified Cochran's formula for sample size calculation in smaller population as following:

$$
\mathrm{n} 2=\frac{\mathrm{n} 1}{1+[(\mathrm{n} 1-1) / \mathrm{N}]} \quad \text { Equation } 2
$$

Where, $\mathrm{N}$ is the total population size available during study period $(\mathrm{N}=280)$

$\mathrm{n} 2$ is the new adjusted sample size 
The new sample size derived was 267.13. However, the study was conducted in 268 patients.

The study was limited in lip and palate area so oblique facial cleft patients were excluded. Written consent was taken prior to procedure from the parents of the patient. A record of the type of cleft, predominance of sex and laterality of cleft, familial history, associated anomalies and drug and disease history of mother during pregnancy was kept. A positive family history was recorded if any of the relatives of the cleft patients was affected with cleft lip and/or palate. A record of other congenital anomalies associated with cleft lip and/or palate which was either apparent or diagnosed earlier was noted. The record of the exposure to teratogenic factors during critical period of first 2 months of embryonic life was noted by taking history. The data were collected, compiled and analyzed by using Excel and Statistical Package of Social Science (SPSS15) software.

\section{RESULT}

\section{Distribution pattern of different cleft types}

According to the data obtained from department of plastic surgery of Kathmandu Model Hospital, the distribution of 268 cleft lip and/or palate patients within the three main types of clefts was: $23.51 \%$ Cleft Lip( CL), 54.85\% Cleft Lip with Cleft Palate (CLP) and $21.64 \%$ Cleft Palate (CP). A preponderance of males was noted when all cleft types were pooled. Males were $58.21 \%$ of all the cleft subjects whereas females were $41.79 \%$ of the subjects.

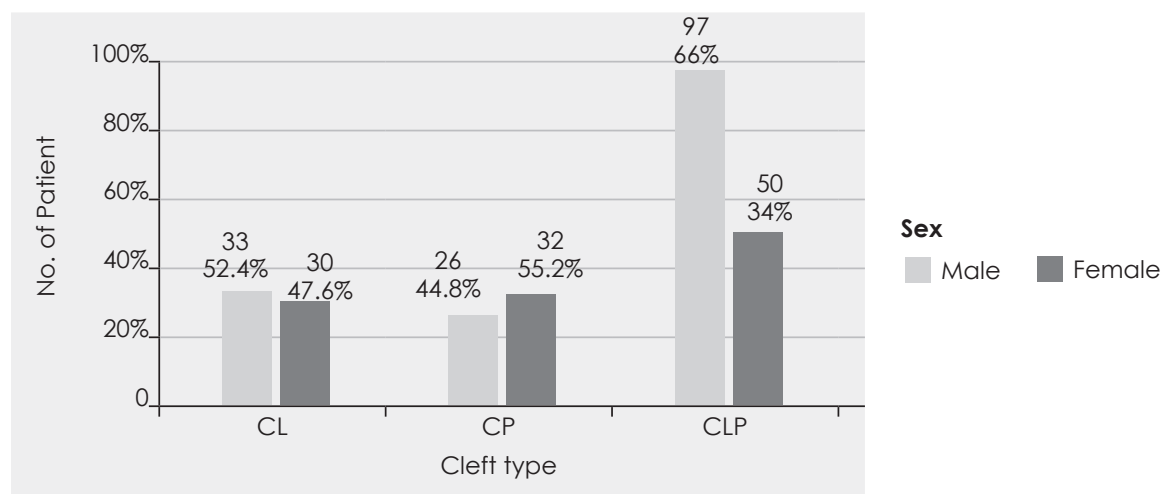

Figure 1: Bar diagram showing sex distribution in different cleft types

Table 1: Distribution of cleft types according to laterality

\begin{tabular}{|c|c|c|c|c|c|}
\hline \multirow{2}{*}{ Cleft Type } & \multicolumn{4}{|c|}{ Laterality } & \multirow{2}{*}{ Total } \\
\hline & Midline & Right & Left & Bilateral & \\
\hline $\mathrm{CL}$ & $1(1.6 \%)$ & $29(46.0 \%)$ & $31(49.2 \%)$ & $2(3.2 \%)$ & $63(100.0 \%)$ \\
\hline $\mathrm{CP}$ & $58(100.0 \%)$ & $0(0 \%)$ & $0(0 \%)$ & $0(0 \%)$ & $58(100.0 \%)$ \\
\hline CLP & $0(0 \%)$ & $44(29.9 \%)$ & $67(45.6 \%)$ & $36(24.5 \%)$ & $147(100.0 \%)$ \\
\hline Total (including midline) & $59(22.0 \%)$ & $73(27.2 \%)$ & $98(36.6 \%)$ & $38(14.2 \%)$ & $268(100.0 \%)$ \\
\hline \multicolumn{2}{|c|}{ Total (excluding midline) } & $34.9 \%$ & $46.8 \%$ & $18.2 \%$ & $100.0 \%$ \\
\hline
\end{tabular}

\section{Background variables}

\subsection{Familial Data:}

Table 2: Family history in each cleft type

\begin{tabular}{|c|c|c|c|}
\hline \multirow{2}{*}{ Cleft Type } & \multicolumn{2}{|c|}{ Family history } & \multirow{2}{*}{ Total } \\
\cline { 2 - 4 } & Absent & Present & $63(100.0 \%)$ \\
\hline $\mathrm{CL}$ & $56(88.9 \%)$ & $7(11.1 \%)$ & $58(100.0 \%)$ \\
\hline $\mathrm{CP}$ & $50(86.2 \%)$ & $8(13.8 \%)$ & $147(100.0 \%)$ \\
\hline CLP & $134(91.2 \%)$ & $13(8.8 \%)$ & $268(100.0 \%)$ \\
\hline Total & $240(89.6 \%)$ & $28(10.4 \%)$ & $260 \%$ \\
\hline
\end{tabular}


2.2 Associated Anomalies: Ten children (3.7\%) had associated congenital malformations.

Table 3: Associated anomalies with cleft diagnosis

\begin{tabular}{|c|c|c|}
\hline Associated Anomalies & Cleft Diagnosis & Frequency \\
\hline \multirow{2}{*}{ ASD } & CP & 1 \\
\hline & Bilateral CLP & 1 \\
\cline { 2 - 3 } & Left sided CLP & 1 \\
\hline Cryptorchidism & Bilateral CLP & 1 \\
\hline Congenital Inguinal Hernia & Left sided CLP & 1 \\
\hline Syndactyly & Right sided CLP & 1 \\
\hline Ear Tag & Left sided CL & 1 \\
\hline Torticollis & Right sided CL & 1 \\
\hline Club Foot & Bilateral CLP & 1 \\
\hline
\end{tabular}

2.3 Exposure to Teratogenic factors: Among many teratogenic drugs, the mothers of $6.0 \%$ of cleft patients were found to be exposed to alcohol, smoking (nicotine) and cortisone.

Table 4: Exposure to teratogenic agents in each cleft types

\begin{tabular}{|c|c|c|c|c|c|}
\hline \multirow{2}{*}{ Cleft Type } & \multicolumn{4}{|c|}{ Exposed to } & \multirow{2}{*}{ Total } \\
\hline & None & Cortisone & Alcohol & Smoking & \\
\hline $\mathrm{CL}$ & 59 (93.7\%) & 0 (0.0\%) & 4 (6.3\%) & $0(0.0 \%)$ & $63(100.0 \%)$ \\
\hline $\mathrm{CP}$ & 57 (98.3\%) & 0 (0.0\%) & 1 (1.7\%) & $0(0.0 \%)$ & 58 (100.0\%) \\
\hline CLP & $136(92.5 \%)$ & $2(1.4 \%)$ & 7 (4.8\%) & $2(1.4 \%)$ & 147 (100.0\%) \\
\hline Total & 252 (94.0\%) & $2(0.7 \%)$ & 12 (4.5\%) & $2(0.7 \%)$ & 268 (100.0\%) \\
\hline
\end{tabular}

2.4 Folic acid (protective agent) intake: The record of intake of folic acid in first trimester of pregnancy was noted by taking history through the questionnaire. None of the mothers of the 268 cleft cases had taken folic acid in first trimester of pregnancy. Those who had taken had started folic acid intake only from the second trimester which is the time period when the development of lip and palate region gets completely developed.

\section{DISCUSSION}

In the present study, CLP was the most common cleft type, followed by CL. These findings are consistent with the findings of the study performed in Denmark and Japan. ${ }^{8,9}$ The findings of Khan in Pakistan, ${ }^{10}$ Aljohar in Saudi Arabia $^{11}$ and Milerad in Sweden'2 also showed that the CLP was the most common type but it was followed by CP group. In contrast to these findings, CP group was most common in the study performed in Korea and France. . $^{13,14}$ Whereas, the CL group was most common in the findings of Singh ${ }^{15}$ and Elahi et al. ${ }^{16}$ The variations in these findings are attributable to differences in case definitions, true population differences, selection of patients, sources of ascertainment and sample size..$^{15}$
The present study showed the predominance of male among the cleft subjects. The gender differences are similar to the findings of Jensen, ${ }^{8}$ Natsume, ${ }^{9}$ Khan, ${ }^{10}$ Aljohar, ${ }^{11}$ and Elahi. ${ }^{16}$ However, the data differs from the findings of $\mathrm{Kim}^{13}$ and $\mathrm{Singh}^{15}$ which showed predominance of female among the cleft subjects. The finding of this study which revealed female predominance among the CP subjects remained similar to the findings of most of the authors $8.11,16$ However, this finding contrast from the finding of Woolf in which males were affected more than female in CP group, as well as, in CL and CLP groups. ${ }^{17}$

In the current study, based on laterality, left-sided cleft was most common in CL and CLP group, followed by right-sided and the least common was the bilateral cleft. The finding is consistent with that of many other authors in which the left sided CL as well as CLP was the most common observation and the least common was the bilateral clefts. $8,11,13,16$

In this study, $28.0 \%$ of the total cases had a positive family history. This finding is quite higher than the finding of Kim in which only $7.0 \%$ of cleft subjects had positive family history. ${ }^{13}$ Similar to present findings, the frequency 
of positive family history was within the range of $21.0 \%$ to $28.0 \%$ in other studies too. ${ }^{16,17}$

Out of the total study population, $3.7 \%$ of patients had other associated congenital anomalies. This finding is lesser than the findings of $\mathrm{Kim}^{13}$ (8.4\%) and Khan ${ }^{10}$ (10.7\%). Whereas, other studies revealed higher percentages ranging from $21.0 \%$ to $47.0 \%$ of subjects associated with other congenital anomalies. ${ }^{10,12}$

Most common associated congenital anomaly in this study was atrial septal defect (ASD) whereas; there were single case each of cryptorchidism, congenital inguinal hernia, ear tag, syndactyly, torticollis and clubfoot. In contrast to this study, Stoll et al found that anomalies of extremities and skeletal system was most common followed by anomaly of central nervous and cardiovascular systems. ${ }^{14}$ These findings are similar to the findings of Jensen et al8 and Milerad et $\mathrm{al}^{12}$ in which malformation of extremity and cardiovascular system accounted for most frequently occurring anomalies. However, the findings of Kim et al is consistent with our finding which showed that $88.0 \%$ of the subjects affected with associated anomalies had congenital heart disease. ${ }^{13}$ Whereas, cryptorchidism as an associated anomaly has been quoted in the paper published by Aljohar et al. ${ }^{11}$

Most investigators have performed study on drug consumption of mother during pregnancy pertaining to the birth of newborns with orofacial clefts. In the current study, it was found that $4.5 \%$ of mothers of cleft subjects consumed alcohol; $0.7 \%$ smoked cigarette and $0.7 \%$ took cortisone. In contrast to these findings, frequent use of analgesic, chemotherapeutic and antineurotic drugs was found during first trimester by mothers of children with cleft in study performed by Saxen. ${ }^{18}$ A relationship between maternal cigarette smoking and risk of orofacial clefts was observed in investigations of Khoury et al and it was stated that clefts were 2 times more frequent in offsprings of smoking mothers than non-smoking mothers. ${ }^{19}$ A study performed to assess the association between the risk of orofacial clefts in infants and use of corticosteroid during pregnancy in Denmark revealed 84 cases among 51973 infants exposed to corticosteroid was affected with cleft. ${ }^{20}$ In an experimental study, the result showed that the young rats of female who received cortisone in addition to vitamin A had $100.0 \%$ incidence of cleft in comparison to those who received vitamin A alone. ${ }^{21}$
Folic acid is known to reduce the incidence of birth defects including the oral clefts. It was found that none of the mothers had started the intake of folic acid in first trimester of pregnancy; and those who did, had started from the second trimester. Similar to our study, lack of counselling and nutritional and vitamin supplements was noticed in mothers in Northern Pakistan. ${ }^{10}$ In a study, increased reduction of oral clefts, in addition to neural tube defects, was observed with folic acid supplementation. ${ }^{22}$ In accordance to this study, a confirmatory laboratory study by concurrent injections of cortisone and vitamin B6 in pregnant mice showed greater degree of protection from clefts in comparison to injection of cortisone acetate alone. ${ }^{23}$

All existing information suggests that orofacial clefts are etiologically heterogenous. A genetic study in population of Utah demonstrated common genetic component for CL and CLP groups; but different for CP group. ${ }^{17}$ In a study, a number of evidence was accumulated to support multifactorial etiology of clefts; which included single mutant gene, chromosomal aberrations, specific environmental agents or interaction of genetic and environmental differences. ${ }^{24}$

\section{CONCLUSION}

Cleft deformities of the lip and/or palate are more commonly seen in males than in females. CLP is the most common type of cleft. CP occurs least frequently. In CLP group, unilateral clefts occur more frequently than bilateral and left side clefts are commoner than right. Positive family history, exposure to teratogenic agents and lack of intake of folic acid is associated with occurrence of cleft. Associated anomalies like atrial septal defect, cryptorchidism, congenital inguinal hernia, ear tag, syndactyly, torticollis and clubfoot may also be present in patients with orofacial clefts.

\section{ACKNOWLEDGEMENT}

I express my most sincere gratitude to Prof. Shaligram Dhungel and Prof. Jay Datta Singh for their guidance, suggestions and encouragement. I am immensely grateful to Dr. Shankar Man Rai without whose support this work would have been impossible.

\section{OJN}




\section{REFERENCES}

1. Peterson LJ, Ellis E, Hupp JR, Tucker MR. Contemporary Oral and Maxillofacial Surgery. 5th Ed. St. Louis (USA): Mosby $2008: 583-603$.

2. Little J, Cardy A, Munger RG. Tobacco smoking and oral clefts: a meta-analysis. Bull World Health Organ 2004; 82: 213-8.

3. Elliot RF, Jovic G, Beveridge M. Seasonal variation and regional distribution of cleft lip and palate in Zambia. Cleft Palate Craniofac J 2008; 45: 533-8.

4. Spilson SV, Kim HJ, Chung KC. Association between maternal diabetes mellitus and newborn oral cleft. Ann PlastSurg2001; 47: 477-81.

5. Romitti PA, Murray JC, Daack-Hirsh S, Burns TL. Cold sores and orofacial clefts. Teratology 2001; 63:252.

6. Khazaei S, Shirani AM, Khazaei M, Najafi F. Incidence of cleft lip and palate in Iran. Saudi Med J 2011; 32(4): 390-3.

7. Singh VP, Sagtani R, Sagtani A. Prevalence of cleft lip and cleft palate in a tertiary hospital in Eastern Nepal. Mymensingh Med J 2012; $21(1): 151-4$

8. Jensen BL, Kreiborg S, Dahl E, Fogh-Anderson P. Cleft lip and palate in Denmark. Cleft Palate J 1988; 25(3): 258-69.

9. Natsume $\mathrm{N}$ et al. Incidence of cleft lip or palate in 303738 Japanese babies born between 1994 and 1995 . Br J Oral MaxillofacSurg 2000; 38(6): 605-7.

10. Khan M, Hidayat Ullah, Naz S, Tahmeed Ullah, Khan H, Tahir M, Obaid Ullah. Patterns of Cleft lip and Cleft Palate in Northern Pakistan. Arch Clin Exp Surg 2012; 1: 63-70.

11. Aljohar A, Ravichandran K, Subhani S. Pattern of Cleft Lip and Palate in Hospital-Based Population in Saudi Arabia: Retrospective Study. Cleft Palate Craniofac J 2008; 45(6): 592-6.

12. Milerad J, Larson O, Hagberg C, Ideberg M. Associated Malformations in infants with Cleft lip and Palate: A Prospective, Population-based Study. Pediatrics 1997; 100(2): 180-6.

13. Kim S, Kim WJ, Oh C, Kim JC. Cleft Lip and Palate Incidence among Live Births in the Republic of Korea. J Korean Med Sci 2002; 17: 4952 .

14. Stoll C, Alembik Y, Dott B, Roth MP. Associated Malformations in Cases with Oral Clefts. Cleft Palate-Craniofac J 2000; 37 (1): $41-7$.

15. Singh VP, Sharma JN, Roy DK, Roy RK. A study of orofacial clefts seen in a tertiary referral hospital in Nepal. Ceylon Med J 2012; 57: 84-5.

16. Elahi MM, Jackson I, Elahi O, Khan AH, Mubarak F, Tariq GB, Mitra A. Epidemiology of cleft lip and palate in Pakistan. J Am Society Plas Surg 2004; 113(6): 1548-55.

17. Woolf CM, Woolf RM, Broadbent TR. A Genetic Study of Cleft Lip and Palate in Utah. Am J Hum Genet 1963; 15: 209-15.

18. Saxen I. Association between oral clefts and drugs taken during pregnancy. Int J Epidemiol1975; 4(1): 37-44.

19. Khoury MJ, Gomez-Farias M, Mulinare J. Does Maternal Cigarette Smoking During Pregnancy Cause Cleft Lip and Palate in Offspring? Am J Dis Child 1989; 143(3): 333-7.

20. Woollam DHM, Millen JW. Effect of Cortisone on the Incidence of Cleft-Palate Induced by Experimental Hypervitaminosis-A. Br Med J 1957; 2(5038): 197-8.

21. Hviid A, Molgaard-Nielsen D. Corticosteroid use during pregnancy and risk of orofacial clefts. Can Med Assoc J 201 1; $183(7)$ : 796-804.

22. Peer LA, Strean LP, Walker JC, Bernhard WG, Peck GC. Study of 400 Pregnancied with Birth of Cleft Lip-Palate Infants: Protective Effect of Folic Acid and Vitamin B6 Therapy. Plast Reconstr Surg Transplant Bull 1958; 22(5): 442-9.

23. Hartridge T, Illing HM, Sandy JR. The Role of Folic Acid in Oral Clefting. Br J Orthod 1999; 26: 115-20.

24. Fraser FC. Review: The Genetics of Cleft Lip and Cleft Palate. Am J Hum Genet 1970; 22(3): 336-52. 